\title{
SURVEYING TO GAUGE STAKEHOLDERS' PARTICIPATION IN URBAN HERITAGE CONSERVATION
}

\author{
M.E. Siguencia Avila ${ }^{1 *}$, D. Avila Luna ${ }^{2}$, M.A. Hermida ${ }^{3}$ \\ ${ }^{1}$ Universidad de Cuenca, Ciudad Patrimonio Mundial (CPM) research project, Faculty of Architecture, 010107 Avenida 12 de Abril \\ s/n y Agustín Cueva, Cuenca, Ecuador - maria.siguenciaa@ucuenca.edu.ec \\ ${ }^{2}$ Universidad de Cuenca, 010107 Avenida 12 de Abril s/n y Agustín Cueva Cuenca, Ecuador - domenica.avilal@ucuenca.edu.ec \\ ${ }^{3}$ Universidad de Cuenca, Departamento de Espacio y Población, LlactaLAB Ciudades Sustentables, Faculty of Architecture, 010107 \\ Avenida 12 de Abril s/n y Agustín Cueva, Cuenca, Ecuador - augusta.hermida@ucuenca.edu.ec
}

Commission II, WG II/8

KEY WORDS: Historic Urban Landscape, community involvement, urban heritage conservation, validated survey

\begin{abstract}
:
Attention to the conservation of urban areas has been already raised in international legal instruments since 1962 and recently gained momentum with the adoption of the Recommendation on Historic Urban Landscapes (HUL) in 2011 (henceforth referred as the 2011 Recommendation). Considering heritage areas as drivers of economic growth but also targets of development pressures, many cities have adopted the tools provided in the 2011 Recommendation depending on their specific geographic and socio-economic contexts testing various systems to innovate in matters of urban heritage conservation and sustainable development. The present research targets the reporting of the process of implementation of the 2011 Recommendation through the creation of a survey to gauge the participation of stakeholders in worldwide case studies to establish a comparative framework. The methodology used for the survey originates from a specific case, Cuenca in Ecuador, and the secondary data collection from 101 additional case studies. The hypothesis is that the questionnaire can compile data as a tool to compare the processes for the implementation of the 2011 Recommendation and to find trends in the cases where stakeholders have become skilled at conserving urban heritage. The design of the survey demonstrates the feasibility to carry out an exploratory validation method (COSMIN) to use significant evidence coming from active stakeholders. The survey as developed becomes a powerful tool to be adapted in different contexts and as a scientific method to reach a proper statistic confidential level, margin error and to control bias in the sample composition.
\end{abstract}

\section{INTRODUCTION}

\subsection{Background}

The conservation of urban areas as such is not necessarily a new approach (Jokilehto, 2007), however, the considerably recent recommendation adopted by UNESCO in 2011, known as the Recommendation on Historic Urban Landscapes (HUL), is being voluntarily worldwide implemented by State Parties interested in preserving values at urban level. The reporting of this implementation process has been assumed by the UNESCO, which in 2015 emitted the first official examination, recognising the development of activities regarding the implementation of the 2011 Recommendation through conferences, technical meetings, workshops and projects in pilot cities where the suitability of this approach has been tested.

The second examination, in 2019 , is intended to constitute a presentation of the consolidated report at the General Conference at its 40th session. This document aims to focus in the monitoring of the progress made in Member States through a questionnaire that reports measures taken in relation to policies, capacity-building, research, information technology, and communication, and results achieved, as well as challenges therein (UNESCO, 2017a). This questionnaire, together with another developed as an initiative of the Organisation of World Heritage Cities (OWHC) during 2018 (Rosetti et al., 2018; UNESCO, 2017b), target the responses from stakeholders including, administrators and experts. In this framework, this study develops a questionnaire based on the in-depth analysis in the local context of Cuenca in Ecuador, sharpened and statistically validated for worldwide cases involved in the implementation of the 2011 Recommendation.

\subsection{Study area}

Cuenca in Ecuador is only one of the many cities that have adopted the tools provided in the HUL approach through the 2011 Recommendation to face the urban expansion among other forms of urban pressures. Worldwide, several cases have adopted it depending on their specific geographic and socioeconomic contexts testing various systems to innovate in matters of urban heritage conservation and sustainable development. The identification of these cases was previously developed through secondary data collection from online sources. This consists of an unprecedented work to identify case studies with evidence of activities related to the implementation of 2011 Recommendation. In this previous stage, 102 case studies were recognised between 2015 and 2017 through a systematic review of academic literature published during the last decade. Since 2007, there are traces of activities carried out in the framework of the understanding of the HUL approach and the implementation of the 2011 Recommendation through initiatives that include, among others, meetings, research projects, workshops, scientific publications, and training sessions.

\footnotetext{
* Corresponding author
} 


\subsection{Objectives and outcomes}

The present research aims at the creation of a survey that reports the process of implementation of the 2011 Recommendation in worldwide case studies and the establishment of a comparative framework based on the results achieved in the case of Cuenca. The questionnaire composed of open-ended surveys was designed following the Consensus-based Standards for the selection of health Measurement Instruments (COSMIN). The objective was to guarantee the statistical reliability of the results through a scientific validated instrument for data collection. Also, the introduction of COSMIN validation system, wider used in health approaches, into the field of urban conservation represents a great innovation to improve the quality of the data collection tools. Besides, unlike the questionnaires developed by UNESCO and the OWHC, the objective is not to limit the responses to administrators and experts but to include an ample group of stakeholders. As for an integration of this larger group of stakeholders, the helices included in the Quadruple Helix $(\mathrm{QH})$ for innovation, are used. The creation of the questionnaire enables the establishment of a comparative framework outlined in topics related to the HUL notion, useful for worldwide and regional analysis. The common framework for comparison is crucial for understanding how the HUL approach is implicit or not in the conservation of urban heritage in different geographic and socio-economic contexts.

\section{PARTICIPATORY URBAN HERITAGE CONSERVATION}

\subsection{The 2011 Recommendation for urban heritage conservation}

The 2011 Recommendation is among the latest concepts defined by UNESCO, which has proven to be an innovative method for the preservation and heritage management of historic cities (UNESCO, 2011a, 2011b). However, it needs to be understood more as a management toolset than a protective measure. With this recent approach, backed by the Vienna Memorandum, both cultural and natural values, contemporary architecture, historic buildings, and open spaces merge together (UNESCO, 2005). The HUL approach overcomes the idea of studying isolated individual buildings, and instead, it studies essential parts, the building setting, and the social participation coordinated both by the citizens and by the diverse public authorities. This approach considers the place itself, the city's profile, the visual axis, types of buildings, open spaces, topography, vegetation, infrastructures, archaeology, anthropology, contemporary architecture, etc., thus proposing a broader vision (Bandarin \& Van Oers, 2014). In fact, it does so to such an extent that new tools and resources are considered to be imperative, tools that differ greatly from those that are currently being used for the conservation and management of the values of cultural heritage (Bandarin \& Van Oers, 2012; Fredheim \& Khalaf, 2016).

The HUL approach is not only based on cultural heritage but is also based on aspects that are currently considered to be at the centre of sustainable development. It addresses issues such as inclusiveness, social cohesion, inequality and segregation, economic and social improvements, housing and environmental needs, and urban regeneration (Cervelló-Royo \& Peiró-Signes, 2015). The definition of HUL itself in the 2011 Recommendation expands the object of study to cover the entire city and its surroundings. In addition, multiple so-called layers of information make up the urban-territorial set (UNESCO, 2011b). Veldpaus and Pereira argue that: "the main purpose of the HUL notion is to provide guidance on sustainable urban management, considering an integrated approach, management of the significance of urban landscapes within an overall sustainable development framework" (2013, pp. 3). According to the 2010 draft proposal for the 2011 Recommendation, the development of a six-step Action Plan constitutes a process that, even if not adopted along with the official text of the 2011 Recommendation, suggests a roadmap for how the HUL approach could be practically implemented in cities (Roders, 2013). The detail of the activities immerse on the six-step Action Plan consists of: step 1) mapping of resources; step 2) reach of consensus / value assessment; step 3) vulnerability / risk assessment; step 4) integration into the city's development / urban plan; step 5) prioritisation of actions; and, step 6) establishment of partnerships / agreements.

\subsection{Case studies implementing the 2011 Recommendation}

The examination of documents developed by UNESCO on the monitoring of the 2011 Recommendation point out the advances of worldwide implementation. First, in the summary of the Reflection Meeting on the implementation of the Recommendation on the Historic Urban Landscape two years after its adoption (2013), regionally, activities in Asia, the Pacific, and Africa are considered as the most relevant samples of implementation. Meanwhile, in Europe workshops and conferences took place particularly among experts where Arab experiences were presented as case studies to prove the feasibility of the implementation. The region of Latin America and the Caribbean is only mentioned at the examination document in 2015, where the regions of Africa and Arab States join to the regions that are suggested to host meetings, workshops and conferences for allowing the implementation. Finally, the second examination of 2019 is intended to report the different ways the recommendations' implementation focused on the questionnaire responses of focal points in Member States. High expectations on the state of the implementation are foreseen for Latin America and the Caribbean since this is the region that has the least number of text reports within the official recommendation monitoring documents.

\subsection{Quadruple Helix (QH) Model for stakeholders}

The concept of innovation has been deeply explored in the business market, specifically in economic development since the 1900s. It explores the roles of the different institutions recognised as key stakeholders (Etzkowitz \& Leydesdorff, 1995). As described by Arnkil (2010), innovation has moved from linear model to innovation systems, territorial innovation models, to the Triple Helix (TH) model and finally to the QH model (Arnkil et al., 2010) (figure 1). The $\mathrm{QH}$ as a model of innovation reflects in many ways several features common to new thinking in the innovation process and innovation policy (Arnkil et al., 2010). Furthermore, the use of the QH model has been evidenced for conceptualising smart tourism in cities as Amsterdam where private and public agencies, as well as residents and academic institutions, are involved (Boes, Buhalis, \& Inversini, 2015).

In the present research, the $\mathrm{QH}$ is spatially specific corresponding to a territory, where cities conserving their urban heritage take a leading role when dynamically working with governments, universities, industries and civil society. As supported by Asheim and Gertler, geography is fundamental, not incidental, to the innovation process itself "one simply cannot understand innovation properly if one does not 
appreciate the central role of spatial proximity and concentration in this process" (2005, pp. 292). In the understanding of the $\mathrm{QH}$, not only the users' involvement and the territory where they interact are relevant to have an idea on the existing dynamics, but also, and not less important, the roles they play. In these roles, since the $\mathrm{QH}$ stresses the civil society helix, the comprehension of the role of this helix in relation to the rest of the helices is rather complex.

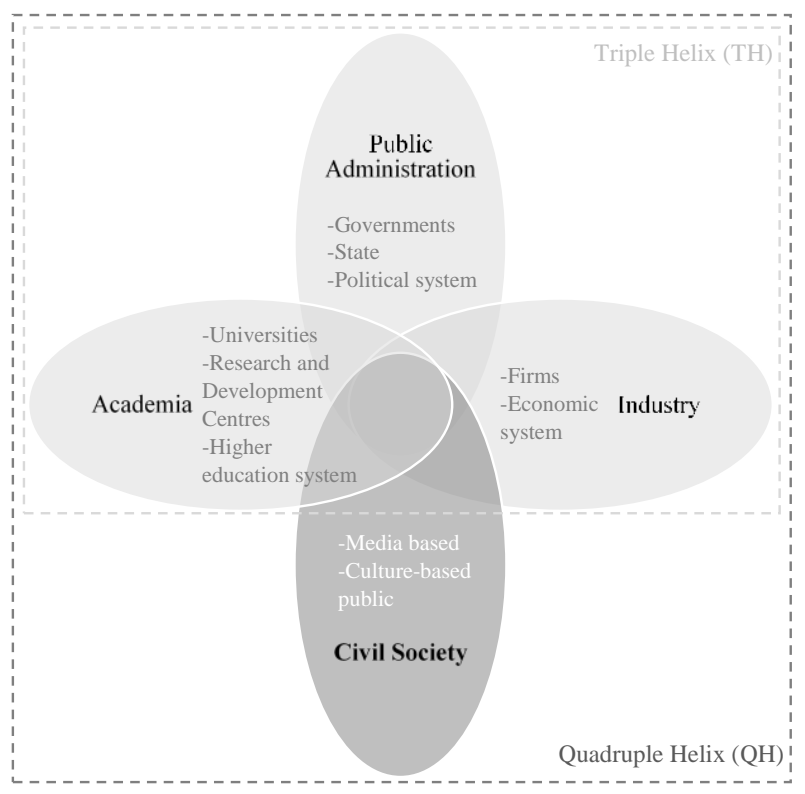

Figure 1. Triple and Quadruple Helix models

\section{METHODOLOGY}

\subsection{Questionnaire for social reality measurement}

The study of the measurement process of social reality (Francés García et al., 2014) supports the development of this research. Along the analysis carried out, statistics are aimed to reveal the actual level of social participation that will be studied in different cases. Although a questionnaire constitutes a research based on a sample of respondents using standardised instruments of questions and answers to obtain quantitative measurements, it is important to emphasise that the results are indicative and can be understood in different manners.

The resulting questionnaire proposed in the coming section comes from the understanding of the stakeholders' involvement in the implementation of the 2011 Recommendation. As for this understanding, the $\mathrm{QH}$ model is used under the description of the four helices as follows: public administration (politicians, councilmen, civil servants); academics (universities, researchers, schools); civil society (citizens, owners, lodgers' associations); and industry (companies, investors, real estate agencies, counsels).

\subsubsection{Questionnaire design and sampling}

The process of social reality measurement needs to start by setting-up the idea on what needs to be measured; this is called defining the construct (Arribas, 2004, pp. 24). The validity of the construct will imply the degree to which the measuring instrument reflects the relevant theories of the phenomenon it measures. Once the constructs are established, the content of the questionnaire defines the target population, the managing and format of the questionnaire. The variables to be measured are based on the operationalisation of the objectives and hypothesis converted into constructs and expressed in dimensions indicators and category systems. These aspects are important to bear in mind, as they will also require the questions to be worded differently or even formatted differently.

Questions are proposed in multiple dimensions (cognitive, assessment, or behavioural) according to the objective of each construct. The indicators are observable characteristics that can be standardised through category systems. These systems need to be exhaustive and inclusive, which means that all possibilities of answers are exposed to selection throughout the questionnaire (Francés García et al., 2014, pp. 58). One of the most widely used category systems, the Likert Scale, is adopted for this study and this includes five levels ranging from totally disagree, disagree, neutral, agree and totally agree.

\subsubsection{COSMIN validation process}

COSMIN stands for Consensus-based Standards for the Selection of Health Measurement Instruments and it consists of an initiative that aims for the improvement of the selection of health measurement in medicine. The objective of the COSMIN initiative is to provide tools for evidence-based instrument selection. One of these tools is the COSMIN checklist (Mokkink et al., 2012). The COSMIN checklist was developed through an international Delphi Study (Mokkink et al., 2012) with the participation of experts from health and statistics fields. To establish the validation method, some measurement properties were considered: internal consistency, reliability, measurement error, content validity, construct validity, criterion validity and interpretability. As a result, it is possible to define if a study meets the standards for good methodological quality (Terwee et al., 2012). Since this tool was conceived with a focus on evaluating the methodological quality of studies on measurement properties of Health Related-Patient Reported Outcomes (HR-PRO), the ongoing research adopts this method because it measures data not directly measurable, multidimensional concepts or constructs. The COSMIN checklist can be completed through four steps:

1. Determine which measurement properties are pertinent to be completed.

2. Complete the Item Response Theory (IRT) box if IRT methods were applied in the article.

3. Complete the corresponding boxes regarding each property marked in step 1 .

4. Complete the Generalisability box for each property marked in step 1.

\section{RESULTS}

\subsubsection{Questionnaire hypothesis and objectives}

Considering 102 case studies identified, it is aimed to track the implementation of the 2011 Recommendation, according to the following constructs: (1) the actual awareness of urban heritage conservation in the territory and the activities carried out to allow such conservation; (2) the stakeholders involved in these activities; and, (3) the level of awareness regarding the implementation. As for construct (1), the aim is to explore the values attributed to the territory as well as the relationship between urban planning and heritage conservation considering that the 2011 Recommendation tackles their integration to conserve urban heritage. Regarding the activities carried out, 
the implementation of the 2011 Recommendation is measured based on the development of the six-step Action Plan. Stakeholders' involvement (2) is established for the activities in (1), and the goal is to recognise how the different helices from the QH model participate in the processes for urban heritage conservation and to what extent they are committed to doing so. Finally, the questionnaire looks at the level of knowledge regarding the implementation of the 2011 Recommendation (3) as well as its awareness among stakeholders from the $\mathrm{QH}$ model. The analysis grasps on to what extent the 2011 Recommendation is being implemented either under this concept or without even being aware of it. It is worth mentioning that the target audience for completing the questionnaire corresponds to the set of stakeholders directly linked to the activities from the secondary data collection developed prior to this research namely, participants involved in the implementation of the 2011 Recommendation in the case studies.

\begin{tabular}{|c|c|c|}
\hline $\begin{array}{c}\text { Statistic } \\
\text { confidential level }\end{array}$ & Error margin & $\begin{array}{c}\text { Total respondents } \\
\text { needed }\end{array}$ \\
\hline $95 \%$ & $5 \%$ & 81 \\
$95 \%$ & $7 \%$ & 68 \\
$90 \%$ & $5 \%$ & 75 \\
$90 \%$ & $7 \%$ & 59 \\
\hline
\end{tabular}

Table 1. Responses needed for statistic accuracy levels

\begin{tabular}{|l|c|l|}
\hline \multicolumn{1}{|c|}{$\begin{array}{c}\text { Evaluated } \\
\text { measurement } \\
\text { properties } \\
\text { (step 1) }\end{array}$} & $\begin{array}{c}\text { Determining if a study } \\
\text { meets the standards for } \\
\text { good methodological } \\
\text { quality } \\
\text { (step 2) }\end{array}$ & $\begin{array}{c}\text { Determining the } \\
\text { Generalisability of } \\
\text { the results }\end{array}$ \\
\hline (step 3)
\end{tabular}

Table 2. Instructions for completing the COSMIN checklist adopted for the study

\subsubsection{Sample design and measurable variables}

In the 102 case studies identified, the ideal statistic confidential level is of $95 \%$ and $5 \%$ of error margin. These percentages correspond to 81 responses needed. However, in the most critical situation, the minimum statistic confidential level is of $90 \%$ and $7 \%$ of error margin (59 responses). The error margin can drop to $7 \%$ and still has representativeness in a sample design (Table 1).

\subsubsection{Validation process}

The validation of the questionnaire was done through the COSMIN checklist in order to guarantee its validity in statistical terms and, consequently, to constitute a proven worldwide tool to be later used for different purposes. The intention of using this tool for validation requires a selection and adaptation of the inputs available. The following steps were adopted for completing the COSMIN checklist (table 2):

1. Step 1: Evaluating measurement properties;

2. Step 2: Determining if a study meets the standards for good methodological quality;

3. Step 3: Determining the Generalisability of the results.

In step 1 , the evaluation of the measurement properties, 8 out of the 11 properties were selected for their applicability in the current research, bearing in mind the medical nature under which this method was originated. In step 2 , it was possible to go through all properties in step 1. In step 3, for the purpose of generalise, an analysis of the results intended was crosschecked. Once the 8 properties were adopted for this study in step 1 , the next step consisted in a validation of the achievement of the standards required (step 2). A summary of the properties is described in the coming paragraphs.

In the first step, internal consistency pursues the identification of missing items and their adequate description. In the 102 cases identified for the application of the questionnaire, there are missing items possibly due to their non-availability in online sources, and to the period in which the selection of cases took place. Cases that were available online after 2017 were not included. A description of the activities carried out in the cases not included in this study can be found through official UNESCO websites about the HUL (UNESCO, 2017b), and in the Second Consolidated Report on the Implementation of the 2011 Recommendation in 2019. The internal consistency of the questionnaire also relates to the sample size, aiming the ideal and an acceptable confidential level and error margin. These figures were defined with a minimum of 65 cases required and an ideal of 78 out of the 102-case studies scope for an adequate sample size. The number of participant cases was 74 reaching $95 \%$ statistic confidential level and a $6 \%$ error margin. As for reliability, the initial draft of the questionnaire was proposed in May 2017 and completed in July 2017 with a first expert review board composed of 5 specialists from KU Leuven, TU/e Eindhoven and Universidad de Cuenca. During October and November 2017, researchers and experts - working on similar research methods (Rosetti et al., 2018)- tested the questionnaire and did a cross-cultural review of the topics related to cultural comprehension and stakeholders' participation. The main changes obtained from this board included a revision of the four main topics addressed by the questionnaire that initially consisted of (i) background on the implementation of the 2011 Recommendation, (ii) stakeholders' categories, (iii) stakeholders' involvement, and (iv) activities carried out. The suggestions aimed at modifying the way of approaching the respondents in (i) from introducing directly the questionnaire based on the 2011 Recommendation to infer the activities carried out and verify the actual implementation. This change was adopted to avoid bias from respondents who are not familiar with the 2011 Recommendation and to avoid abrupt refusals to the questionnaire form sceptics on the subject. Another relevant change from the first draft was the method to collect data regarding the involvement of stakeholders in the implementation of the 2011 Recommendation (ii) and (iii). The questions changed so as to link them through a matrix between activities (iv) and stakeholders. The awareness of the 2011 Recommendation was separated from (i) and inserted as the last section of the questionnaire. 
In December 2017, the questionnaire was tested for the first time by a set of 15 researchers from the Faculty of Architecture and Urbanism for the case of Cuenca. From this test in a socalled local questionnaire (LoQ), bias was detected in the section that referred to stakeholders since respondents were exclusively academics. Thus, questions related to the respondents' expertise and their appreciation about the participation of other groups of stakeholders were included. In this way, the questionnaire was restructured in the topics related to territory, stakeholders, and awareness about the 2011 Recommendation and in this way content and structural validity, as well as the hypothesis, tested in said sections. Although an accurate reliability level requires a two-measurement, for the socalled international questionnaire (InQ) (see appendix) the sample size is quite large in terms of responsiveness. In this case, the alternative method for reliability and cross-cultural validation at this stage comprises an expert representative board composed of two to three participants per region to assess both, cultural feasibility and language constraints in their contexts. The validation from experts took place during March 2018. The original language instrument created in Spanish was verified for its translation to English, also as part of the cross-cultural validity. The cross-cultural validity requires a forward and backward translation and a final review from a council. This process was developed together with the abovementioned expert board. In February 2018, a native English speaker with experience on related subjects was requested to evaluate the translation and confirm a cross-cultural understanding between both languages.

Lastly, the questionnaire was uploaded to the online platform Google Forms in April 2018; its proposal included the option to select the language preferred (English and Spanish) to respond to the questionnaire. The distribution of the questionnaire was, in a first stage, via personal email to a list of target participants of the 102 case studies. In most cases, in the absence of reaction, more than one person was contacted. In a second stage, reminders were sent to the target contacts that had not participated yet, including a note on the possibility to share the questionnaire among colleagues in case of unavailability of time. Finally, the questionnaire was also opened to the public via social media and therefore the participants were not limited to the target ones.

As for step 3 of the validation process, the generalisability of the results is evidence-based on the settings in which the questionnaire was conducted. In the 58 countries in which the 102 cases are spread, in spite of their cultural difference, for the aim of this research they are subject to verification on the circumstances that led them to initiate activities towards the conservation of urban heritage.

\subsubsection{Final scheme proposed}

The validated questionnaire proposed for the 102 case studies InQ and the one for the case in Cuenca LoQ include a presentation indicating the objective, guarantee of confidentiality and an overview of the data surveyed. The InQ consists of a total of 14 questions that include 5 General Questions surveying the respondents' background and 9 socalled Core Questions divided into 3 sections (coming from the established constructs). The LoQ is composed of 16 questions containing the same 9 Core Questions as in the InQ, 6 General Questions, and 3 Evaluation Questions. The Core Questions are intended to constitute a common framework for comparison.
Figure 2 shows the scheme of the proposed questionnaire and the shared features between InQ and LoQ. The InQ collected 103 responses. The responses from more than one participant in some case studies led to a collection of 82 responses that correspond to 74 case studies (SET A) out of the 102 total cases identified. The 74 case studies represent a $73 \%$ response rate and to $95 \%$ statistic confidential level and a $6 \%$ error margin. The additional 21 responses correspond to 13 case studies (SET B), which were not part of the 102 case studies identified. This set of case studies was collected since the last stage on the release of the questionnaire was open to the public. Although SET B has not been considered for the analysis in this study, the results for both, SET A and SET B are available in the online platform Story Maps.

Between April 25 and June 8, 2018, the LoQ was released in Cuenca where 77 responses were collected. The target audience is focused on the participants of the activities carried out in Cuenca during the implementation process in the stage of stakeholders' involvement. The structure of the questionnaire is based on the 9 core questions plus 6 general questions that differ from the ones in InQ. The general questions are related to the participants' background in Cuenca including gender, level of instruction, the number of events they have participated in the framework of the implementation process. Finally, to assess the comprehension of the HUL approach of this audience after their involvement in the implementation of the 2011 Recommendation, three evaluation questions are included. The dissemination of the questionnaire was done via personal email to the list of participants in previous events as well as via social media. Participants were motivated with a book drawing to collect as many responses as possible.

\section{CONCLUSIONS}

The proposal of the social measurement through a questionnaire presented advantages and disadvantages for this study. On the one hand, the advantages included: the rich amount of data collected and available once the questionnaire was completed, the practical systematisation of results via digital sources, the possibility of generalisation of topics and the confidential level provided when an accurate sample size was reached.

The adoption of the COSMIN validation process strengthens the reliability of the achieved results and needs to be further used in similar tools to verify its feasibility in the field. On the other hand, the disadvantages dealt with time-bound concerns. In the narrow sample of 102 case studies, the time devoted for reaching first a contact person available to complete the questionnaire and then a minimum number for statistical confidence needed from the said sample exceeded the initial estimated time.

Previous comparative works have demonstrated the feasibility of managing information of three cases through analysis and application of surveys (Martini, 2013; Sandholz, 2016), however, the attempt for an ampler comparison in this research implicated a different perspective where the characteristics of each case study might be disguised. The perception of these referred characteristics in each case study could have also been affected since some of the proposed inquiries of the questionnaire were based on the results obtained from the case of Cuenca. 


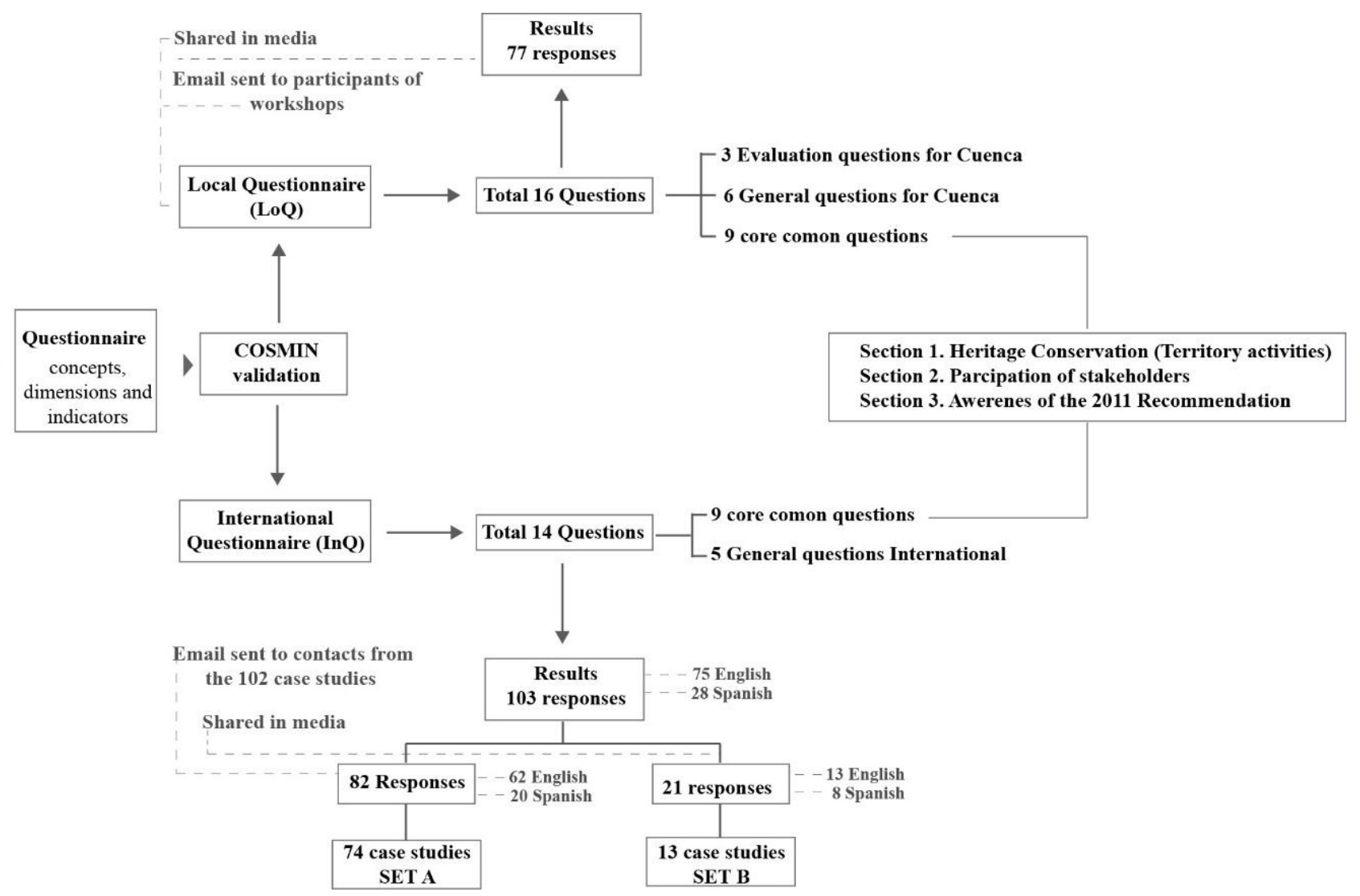

Figure 2. Scheme of the questionnaire proposed for local and international level

This comparative analysis through the use of a questionnaire is a significant methodological contribution since it shifts from specific to general levels, local to international. Although the results of this comparative analysis show the potential of the use of data coming from stakeholders' perception, the use of the quantitative analysis is still questionable. To some extent, the qualitative data collected regarding the characteristics of case studies is not reflected. Therefore, it is concluded that there is a need for a way to compare qualitative and qualitative measurement systems in a combined way.

The exhaustive data compilation through the questionnaire is a valuable source of information. It is desirable that the resources obtained support further and detailed analysis not only in the case studies that have been part of this research, but also the available and ready-to-use data coming, for example, from SET B. Considering that this set of 13 case studies demonstrated an interest in completing the questionnaire, it could be important to know whether they are aware or not about the 2011 Recommendation. These results could show the increasing number of cities committed to implementing the concept of HUL. Besides SET B, additional cases have joined the network of cities adopting the HUL approach. This implies that the number of cases for comparison is increasing and they could complement or influence the results obtained.

\section{REFERENCES}

Arnkil, R., Järvensivu, A., Koski, P., and Piirainen, T., 2010. Exploring quadruple helix outlining user-oriented innovation models (Työraportteja Working Papers No. 85/2010). Institute for Social Research. University of Tampere.
Arribas, M., 2004. Diseño y validación de cuestionarios. In: Matronas profesión, 5(17), pp. 23-29, doi.org/10.35362/rie670230

Asheim, B. T., and Gertler, M. S., 2005. The geography of innovation: regional innovation systems. In: The Oxford handbook of innovation, pp. 291-317.

Bandarin, F., and Van Oers, R., 2012. The Historic Urban Landscape: Managing Heritage in an Urban Century. John Wiley \& Sons.

Bandarin, F., and Van Oers, R., 2014. Reconnecting the City: The Historic Urban Landscape Approach and the Future of Urban Heritage. John Wiley \& Sons.

Boes, K., Buhalis, D., and Inversini, A., 2015. Conceptualising smart tourism destination dimensions. In: Information and communication technologies in tourism. Springer, pp. 391-403, doi/10.1007/978-3-319-14343-9_29

Cervelló-Royo, R., and Peiró-Signes, Á., 2015. Environmental impact of coastline tourism development in Spain. In: Sustainability, Social Responsibility, and Innovations in the Hospitality Industry, pp. 151-170, dx.doi.org/10.4995/ICBM.2015

Etzkowitz, H., and Leydesdorff, L., 1995. The Triple HelixUniversity-industry-government relations: A laboratory for knowledge based economic development. In: EASST European Association for the study of Science and Technology Review, 14(1), 14-19. 
Francés García, F. J., Alaminos Chica, A. F., Penalva Verdú, C., and Santacreu Fernández, O. A., 2014. El proceso de medición de la realidad social: La investigación a través de encuestas. Universidad de Cuenca. PYDLOS.

Fredheim, L. H., and Khalaf, M., 2016. The significance of values: heritage value typologies re-examined. In: IJHS International Journal of Humanity Studies, 22(6), 466-481.

Jokilehto, J., 2007. International charters on urban conservation: some thoughts on the principles expressed in current international doctrine. In: C\&T City and Time, 3(3), 2.

Martini, V., 2013. The Conservation of Historic Urban Landscapes: an approach Vol 2 The methodological approach (PhD thesis). Doctoral dissertation. University of Nova Gorica, Venice.

Mokkink, L. B., Terwee, C. B., Patrick, D. L., Alonso, J., Stratford, P. W., Knol, D. L., and de Vet, H. C., 2012. COSMIN checklist manual. Amsterdam: University Medical Center, doi: 10.1007/s11136-010-9606-8

Roders, A. P., 2013. How can urbanization be sustainable? A reflection on the role of city resources in global sustainable development. In: BDC - Bolletino Del Centro Calza Bini, Università Degli Studi Di Napoli Federico II, 1, 79-90

Rosetti, I., Roders, A. P., Colenbrander, B., and Burgers, G.-J., 2018. Participatory practices in heritage management in world heritage cities: unveiling the city representatives' perceptions. Presented at the 4th Biennial Conference of the Association of Critical Heritage Studies (ACHS 2018), Hangzhou, China.

Sandholz, S., 2016. Urban Centres in Asia and Latin America: Heritage and Identities in Changing Urban Landscapes. Springer.

Terwee, C. B., Mokkink, L. B., Knol, D. L., Ostelo, R. W., Bouter, L. M., and de Vet, H. C., 2012. Rating the methodological quality in systematic reviews of studies on measurement properties: a scoring system for the COSMIN checklist. In: QLR Quality of Life Research, 21(4), 651-657.

UNESCO., 2005. Vienna Memorandum on World Heritage and Contemporary Architecture - Managing the Historic Urban Landscape http://whc.unesco.org/document/115812 (7 January 2019).

UNESCO., 2011a. Proposals concerning the desirability of standard-setting instrument on Historic Urban Landscape http://unesdoc.unesco.org/images/0021/002110/211094e.pdf (15 February 2019).

UNESCO., 2011b. Recommendation on the Historic Urban Landscape (Records of the General Conference No. 36 C/Resolution

http://unesdoc.unesco.org/images/0021/002150/215084e.pdf (9 February 2019).

UNESCO., 2017a. Implementation of Standard-Setting instruments Part VI -Implementation of the 2011 Recommendation on the Historic Urban Landscape, including a glossary of definitions- Preparations for the next consultation (No. 202 EX/24) (19 January 2019).
UNESCO., 2017b. Recommendation on the Historic Urban Landscape. Online Survey https://whc.unesco.org/en/hul/ (8 March 2019)

Veldpaus, L., and Roders, A. P., 2013. Urban Heritage: Putting the Past into the Future. In: The Historic Environment: Policy \& Practice, 4(1), pp. 3-18.

\section{APPENDIX}

International Questionnaire (InQ)

Cities united by urban heritage

\section{Introductory Questions}

1. Select the country and write the case (city/town) you were contacted for

\begin{tabular}{|c|c|c|c|}
\hline \multicolumn{4}{|l|}{ Country } \\
\hline \multicolumn{4}{|l|}{ Case (City / town) } \\
\hline \multicolumn{4}{|c|}{$\begin{array}{l}\text { 2. Indicate your affiliation } \\
\text { 3. How many years have you being working on heritage } \\
\text { practice? }\end{array}$} \\
\hline$<5$ years & 5-10 years & $11-20$ years & $>20$ years \\
\hline
\end{tabular}

Section 1: Heritage Conservation in the case (city/town)

4. What level of importance is given -in general- to the following heritage attributes in the city?

\begin{tabular}{|l|l|l|l|l|l|}
\hline & \multicolumn{5}{|c|}{ IMPORTANCE } \\
\hline & $\begin{array}{l}\text { None (As far } \\
\text { as I am aware) }\end{array}$ & Low & Medium & High & $\begin{array}{l}\text { Very } \\
\text { High }\end{array}$ \\
\hline $\begin{array}{l}\text { Traditional } \\
\text { festivals }\end{array}$ & & & & & \\
\hline Built heritage & & & & & \\
\hline Public spaces & & & & & \\
\hline $\begin{array}{l}\text { Nature and } \\
\text { environment }\end{array}$ & & & & & \\
\hline $\begin{array}{l}\text { Traditional } \\
\text { cuisine }\end{array}$ & & & & & \\
\hline $\begin{array}{l}\text { Identity } \\
\text { (clothing, } \\
\text { dialect) }\end{array}$ & & & & & \\
\hline $\begin{array}{l}\text { Other, specify } \\
\text { and rate }\end{array}$ & & & & & \\
\hline
\end{tabular}

5. To what extent do these statements reflect the reality in your chosen city (please only give one answer per question)

\begin{tabular}{|c|c|c|c|c|c|}
\hline $\begin{array}{c}\text { Totally } \\
\text { disagree }\end{array}$ & Disagree & Neutral & Agree & $\begin{array}{c}\text { Totally } \\
\text { agree }\end{array}$ & Unknown \\
\hline
\end{tabular}

The heritage areas have a specific role that connects them to the rest of the city

Laws or regulations in place for the protection of heritage areas are fully complied

Heritage areas are incorporated into the general planning of the city

Protected buildings and sites are included in the city's planning

Promotion of heritage areas with less vehicles is necessary in the city

Investment in the maintenance and reuse of any heritage buildings is frequently done

There is a relation between architecture and the city's natural environment

There is a promotion of routes and cultural itineraries in which intangible heritage can be seen (history, festivals, traditions, people)

6. How often have the following activities for the conservation of heritage attributes in the city been carried out? If necessary, add any additional activities that have been carried out in your city

\begin{tabular}{|c|c|c|c|c|c|}
\hline Never & Rarely & Sometimes & Usually & Always & Unknown \\
\hline \multicolumn{6}{|c|}{ Mapping of resources / gathering of information } \\
\hline
\end{tabular}




\begin{tabular}{|l|}
\hline Participative workshops to formulate plans and projects in the city \\
\hline Heritage value assessment \\
\hline Heritage risk assessment \\
\hline $\begin{array}{l}\text { Prioritisation of the actions which are considered necessary for the } \\
\text { conservation of the city's important heritage }\end{array}$ \\
\hline $\begin{array}{l}\text { Proposals for intervention in buildings and public spaces with the } \\
\text { respective permits }\end{array}$ \\
\hline Proposals for master plans for areas of heritage value \\
\hline Updating of regulations related to local heritage \\
\hline Publication in the media of the results of the city plans and projects \\
\hline Promotion of academic results through publications \\
\hline Creation of agreements between different institutions and stakeholders \\
\hline Monitoring of results \\
\hline
\end{tabular}

Section 2: Participation of stakeholders in efforts carried out for the conservation of Urban Heritage

Considering the following four key groups of stakeholders:

Public Administration (politicians, councillors, civil servants...

Academics (universities, researchers, schools, colleges...

Civil society (citizens, owners, neighbourhood associations ...

Industry (private sector, companies, commerce, investors, real estate, consultants ...

7. Indicate which group takes the lead of the following activities in the city

\begin{tabular}{|l|}
\hline \multicolumn{1}{|c|}{$\begin{array}{c}\text { Public } \\
\text { Administration }\end{array}$} \\
\hline Mapping of resources / gathering of information \\
\hline $\begin{array}{l}\text { Training courses and seminars on topics related to architecture and } \\
\text { traditional techniques }\end{array}$ \\
\hline Participative workshops to formulate plans and projects in the city \\
\hline Heritage value assessment \\
\hline Heritage risk assessment \\
\hline $\begin{array}{l}\text { Prioritisation of the actions which are considered necessary for the } \\
\text { conservation of the city's important heritage }\end{array}$ \\
\hline $\begin{array}{l}\text { Proposals for intervention in buildings and public spaces with the } \\
\text { respective permits }\end{array}$ \\
\hline Proposals for master plans for areas of heritage value \\
\hline Updating of regulations related to local heritage \\
\hline Publication in the media of the results of the city plans and projects \\
\hline Promotion of academic results through publications \\
\hline Creation of agreements between different institutions and stakeholders \\
\hline Monitoring of results \\
\hline
\end{tabular}

8. In terms of the activities that you carry out for the conservation of heritage attributes in the city; rate your level of participation as a stakeholder within the following groups.

\begin{tabular}{|l|l|l|l|l|l|}
\hline & \multicolumn{5}{|c|}{ Level of participation } \\
\hline & None & Low & Medium & High & $\begin{array}{c}\text { Very } \\
\text { high }\end{array}$ \\
\hline Public administration & & & & & \\
\hline Academics & & & & & \\
\hline Civil society & & & & & \\
\hline Industry & & & & & \\
\hline
\end{tabular}

9. How do you participate in activities related to the conservation of heritage attributes in the city? You may select more than one option

\begin{tabular}{|l|l|}
\hline I am not involved & \\
\hline I have been consulted by entities & \\
\hline I have been informed in meetings & \\
\hline I have been informed by the media & \\
\hline I have participated in workshops & \\
\hline I take the initiative to initiate actions & \\
\hline I participate actively & \\
\hline I make decisions about actions to be carried out & \\
\hline I carry out planned actions & \\
\hline
\end{tabular}

Section 3: Awareness of the Recommendation on Historic Urban Landscapes

In 2011, UNESCO adopted a Recommendation on Historic Urban Landscapes (HUL) that refers to the urban area resulting from a historical stratification of natural and cultural values, and this goes beyond the notion of a "historic centre" to include the general urban context and its geographical setting.

10. How much do you know about the activities that have been carried out in the city for the implementation of the Recommendation on HUL?

I am unaware of any such activity

I am aware of a few activities that have been carried out

I am aware of several activities that have been carried out I am usually aware of most of the activities that are being carried out

I am aware of all the activities carried out

11. How would you describe the state of implementation of the Recommendation on HUL in the city?

The implementation...

Has not started

Has only consisted of a one-time initiative or an isolated activity

Consisted of short-term initiatives which have already finished

Consisted of short-term activities which are currently being carried out Consisted of long-term activities which have already finished

Consisted of long-term activities which are currently being carried out 12. In terms of the different groups of stakeholders. What level of knowledge does each group have with regards to the implementation of the Recommendation on HUL in the city?

\begin{tabular}{|l|l|l|l|l|l|}
\hline & \multicolumn{5}{|c|}{ Level of knowledge } \\
\hline & None & Low & Medium & High & $\begin{array}{c}\text { Very } \\
\text { high }\end{array}$ \\
\hline Public administration & & & & & \\
\hline Academics & & & & & \\
\hline Civil society & & & & & \\
\hline Industry & & & & & \\
\hline
\end{tabular}

13. What other international recommendations, letters or documents are used as guides for Urban Conservation in the city?

14. If you would like to follow up on the results of this survey, please provide us with your email address

Thank you for your cooperation! 